\title{
UNDERSTANDING THE BARRIERS TO LIVESTOCK PRODUCTION IN THE CLAYBELT REGION OF NORTHERN ONTARIO
}

Sara Epp

March 13,2019 - Rural Symposium 


\section{Research team}

Starting premise

Research objectives

OUTLINE

Research activities

\section{Initial findings}

Next steps 


\section{RESEARCH TEAM}

- Joint project between the University of Guelph and Hearst University

- Wayne Caldwell (Guelph) and Sophie Dallaire (Hearst) are project leads

- Additional research assistants from each institution

- Community Advisory Board

- This project has been funded through the New Directions program 


\section{STARTING PREMISE}

- Abundance of under- or unutilized agricultural land within the Clay Belt

- Agricultural expansion is slowly occurring but research is often focused on the consumer

- Limited understanding of the economic, social and environmental barriers to livestock production 


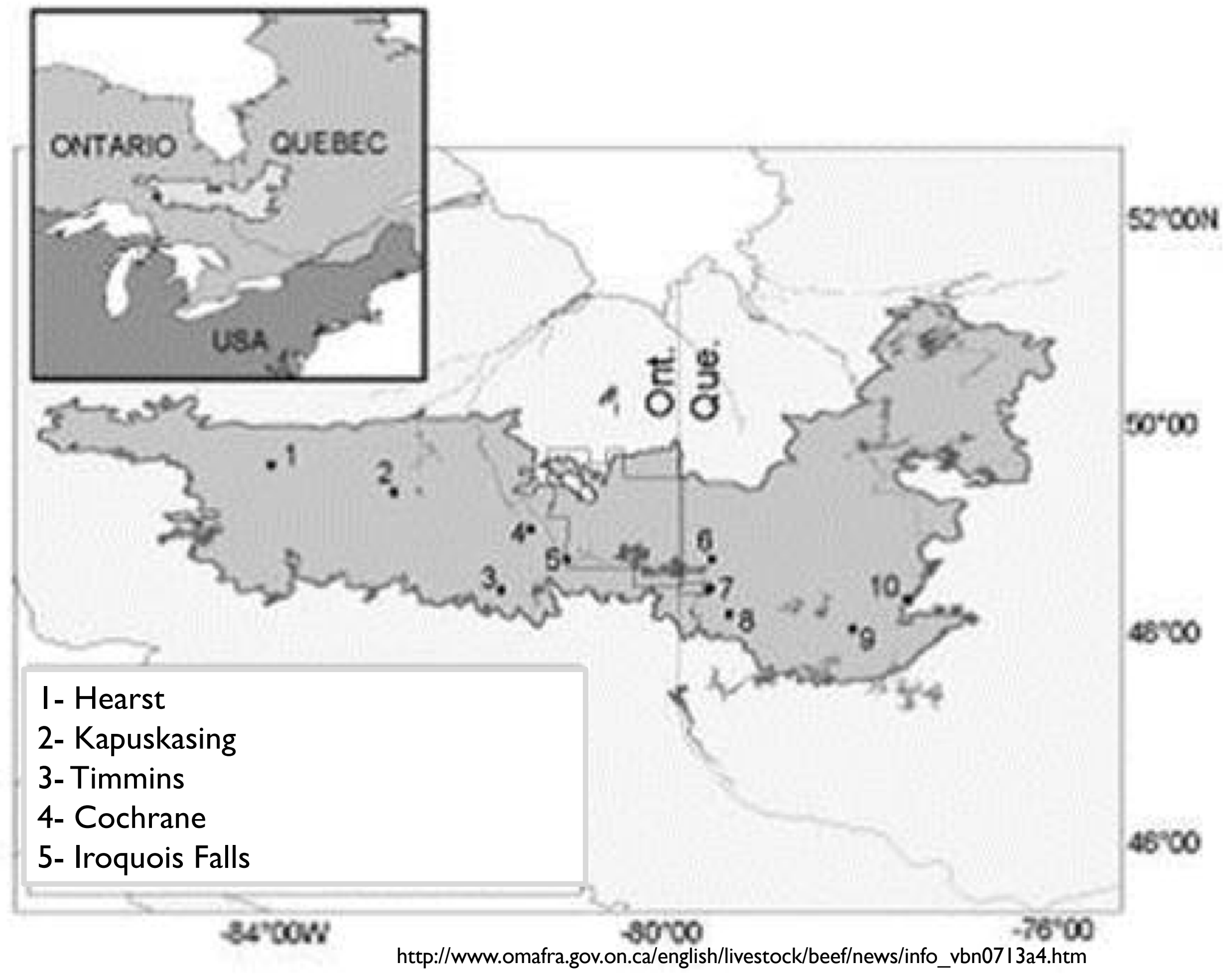


Need to understand the economic, social and environmental barriers to livestock production in the Claybelt Region

How do these barriers impact youth retention, new farmer attraction, and farm expansion?

\section{RESEARCH OBJECTIVES}




\section{RESEARCH PARTICIPANTS}

- Business sector

- Education sector

- Farm organizations

- Farmers (existing)

- Prospective farmers
- Students

- Health Sector

- First Nations

- Mennonites

- Municipalities 


\section{ECONOMIC BARRIERS}
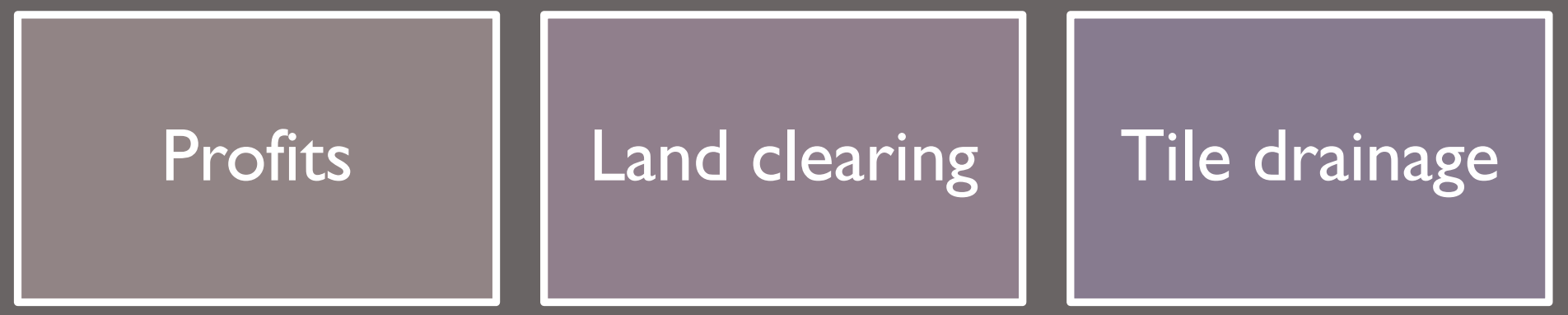

Access to equipment

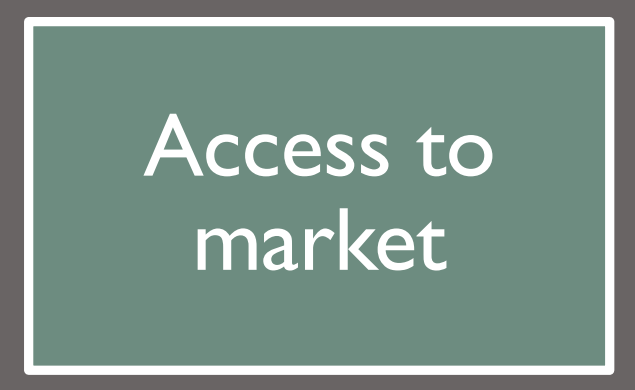

Access to services
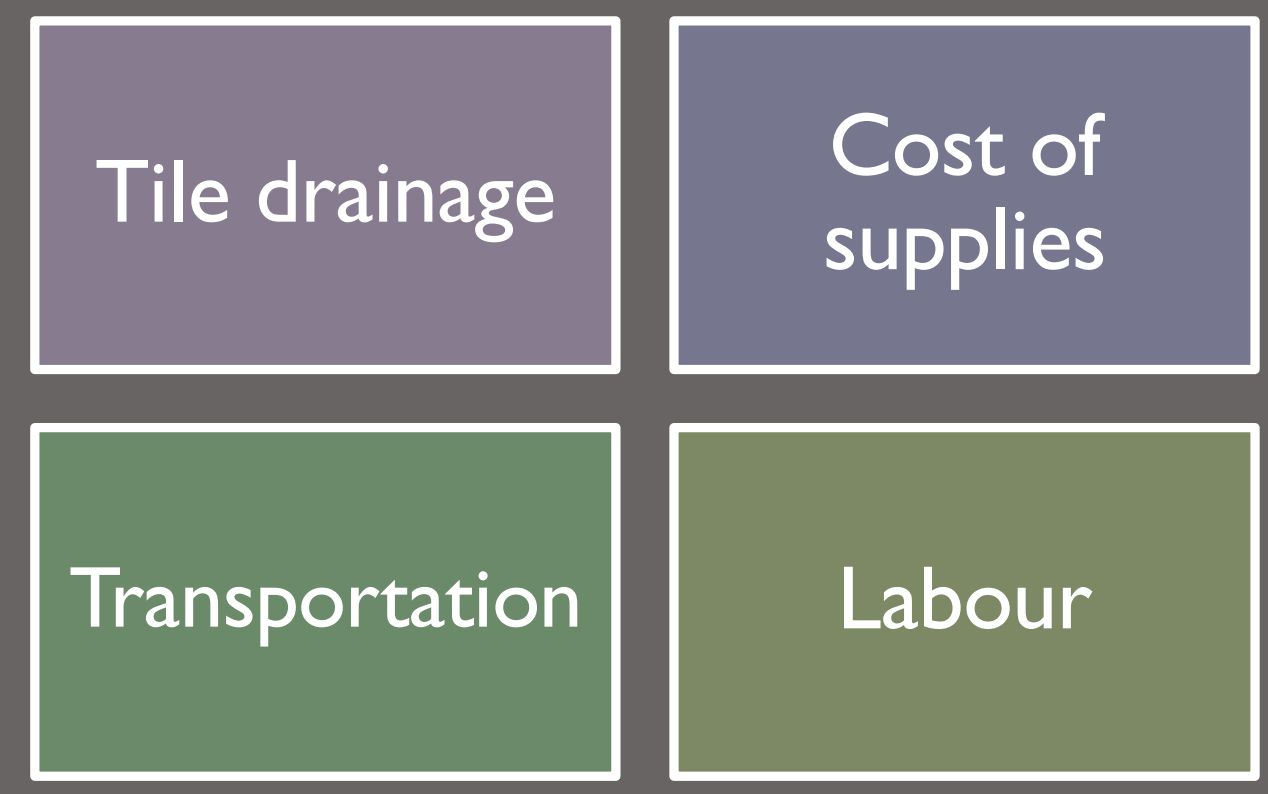

Availability of grants 


\section{SOCIAL BARRIERS}
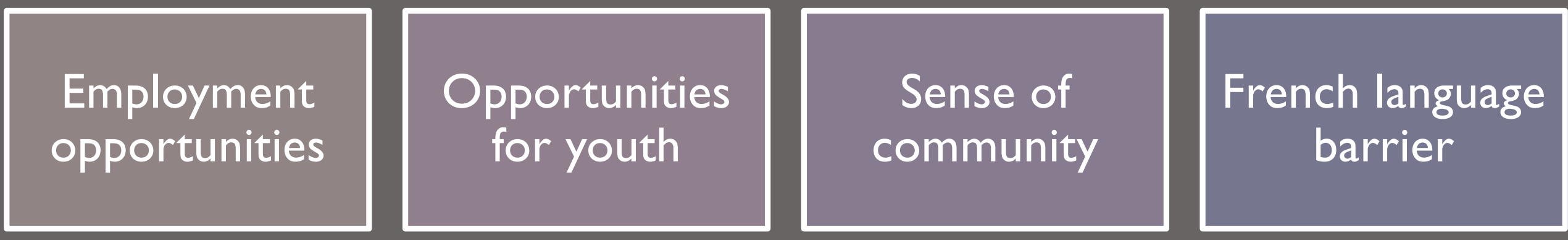

Lack of farming community
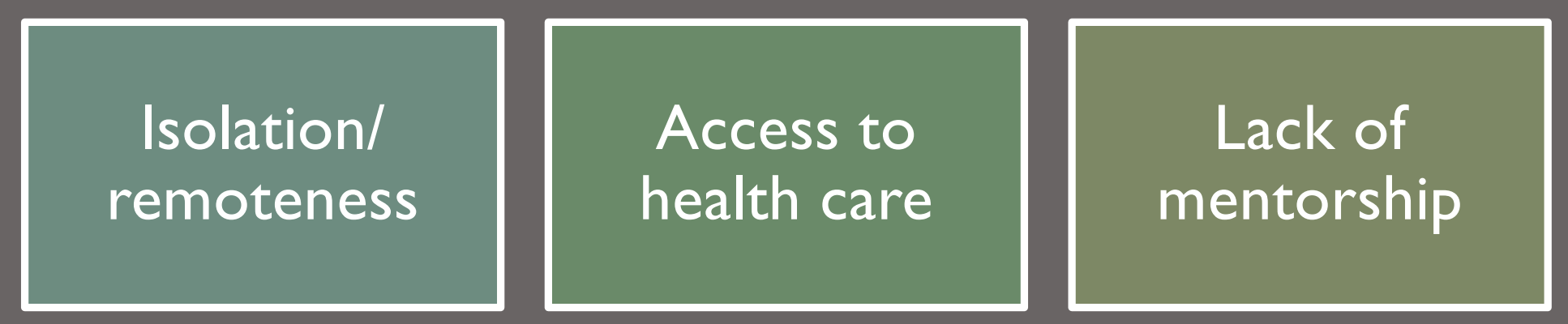

Access to
commercial
businesses/
services

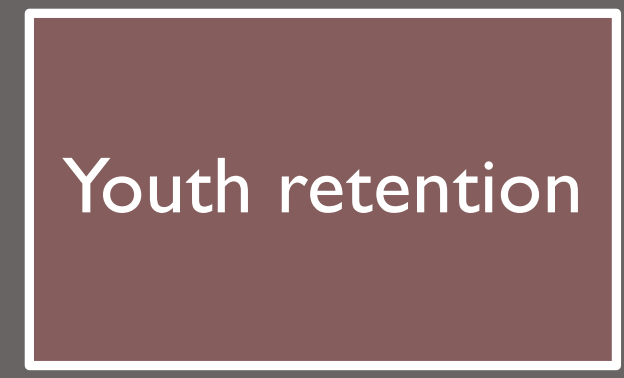




\section{ENVIRONMENTAL BARRIERS}
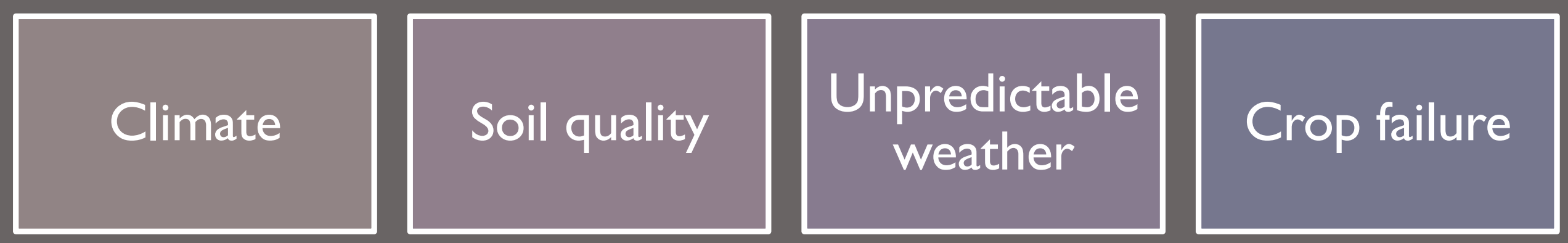

Inability to grow feed
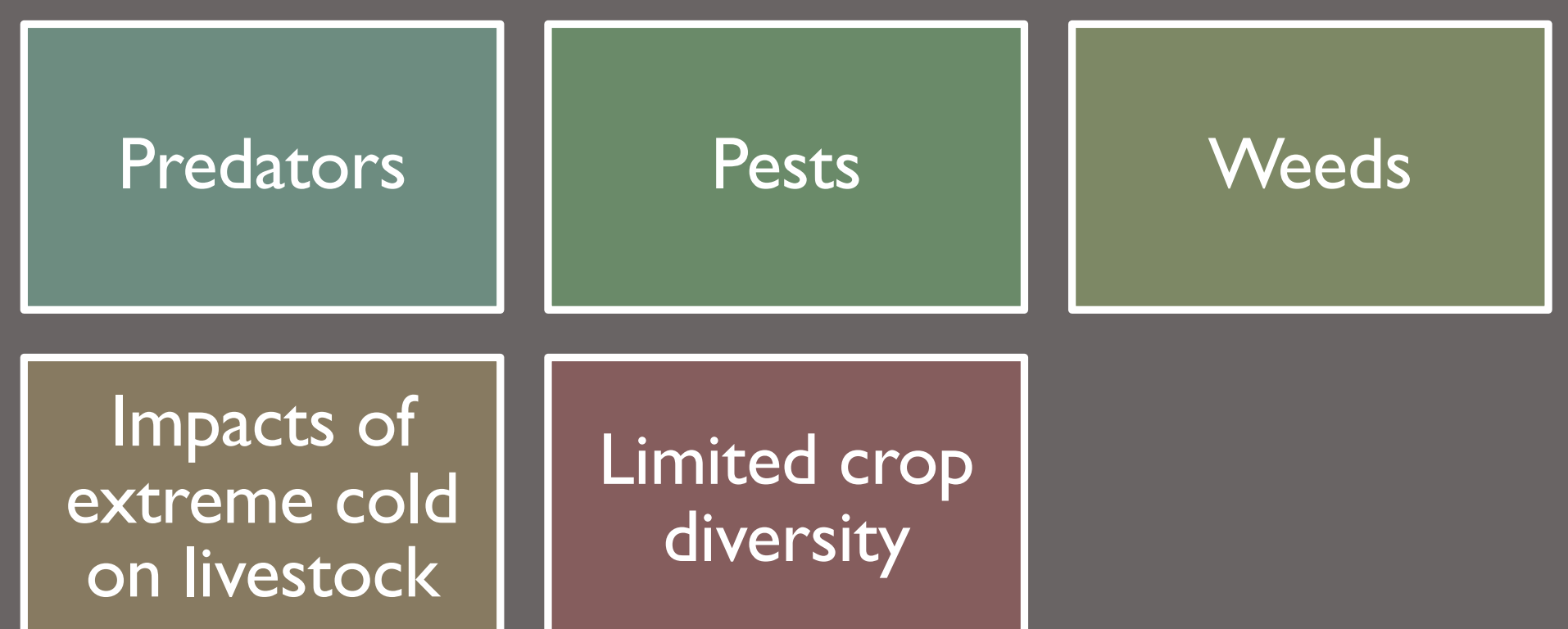

Limited crop diversity 


\section{FINDINGS}

- Perception or reality?

- Economic barriers are a serious concern

- Social barriers are difficult to resolve

- Environmental barriers focused on climate and soil quality

- Significant variation by group 


\section{NEXT STEPS}

- Barriers and solutions report

Share report with community advisory board for feedback

- Finalize report

- Share with all stakeholders 


\section{THANK YOU}

\section{Questions?}

- For more information on this research:

- sepp@uoguelph.ca 